\title{
La formación de un paisaje. El lago del Oeste de Hangzhou desde sus orígenes hasta las Cinco Dinastías
}

\author{
Becoming Landscape: \\ Hangzhou's West Lake from \\ its Origins to the Five Dynasties
}

ANTONIO JOSÉ MEZCUA LÓPEZ*

Resumen: El lago del Oeste de la ciudad de Hangzhou es uno de los más importantes lugares dentro de la historia cultural de China, y aun así hay muy pocos estudios en lenguas occidentales dedicados al tema. En este artículo se pretende hacer un acercamiento al periodo de formación del paisaje del lago del Oeste utilizando las nuevas metodologías interdisciplinares de los estudios del paisaje. Se examina el periodo que hay entre los Reinos Combatientes y las Cinco Dinastías, y se muestran los procesos que intervienen para que un determinado lugar se convierta en paisaje famoso dentro de la cultura china.

Palabras clave: lago del Oeste; Hangzhou; paisaje; China.

Abstract: The city of Hangzhou's West Lake is one of most important places in the cultural history of China, and yet, there is a lack of research about it in western languages. This article intends to approach the period when the West Lake took on identity as a separate "landscape", using new interdisciplinary methodologies on landscape studies. We will review the time between the Warring States and the Five Dynasties periods, demonstrating the processes by which

Recepción: 7 de julio de 2016. / Aceptación: 27 de febrero de 2017.

* Universidad de Granada, amezlopez@ugr.es 
a certain place can take on the identity of a famous landscape in Chinese culture.

Key words: West Lake; Hangzhou; landscape; China.

\section{Introducción}

\section{La cultura del paisaje}

Sin ninguna duda, la ciudad de Hangzhou, con su lago del Oeste, es uno de los más importantes lugares en la historia tanto del paisajismo como del arte chino, que ha inspirado muchas pinturas y composiciones literarias; asimismo, un número incontable de jardines se ha construido en sus alrededores. Al ser incuestionable su valor dentro de la cultura china, no deja de sorprender la poca atención que ha recibido de la historiografía en lenguas occidentales. Sobre el lago del Oeste tenemos la gran obra de Hui Shu-lee acerca de su relación con el arte de la dinastía Song del sur y el monográfico realizado por la revista Chinese Heritage Quarterly, más centrado en las épocas Qing y contemporánea. ${ }^{1}$ Aparte de estos estudios, no hay en lenguas occidentales una publicación monográfica que profundice en la evolución del lago como espacio paisajístico y establezca conexiones entre los diferentes medios de expresión cultural vinculados a éste. El lago del Oeste se nos presenta como un espacio complejo en el que la pintura, las creaciones literarias y el diseño de jardines, además de las distintas ideologías y mitologías daoístas, budistas o confucianas, forman una red imbricada de difícil separación. Por esto se necesita un análisis interdisciplinar que permita una mirada global y unifique los diferentes acercamientos humanísticos, como los estudios literarios, la historia del arte o la historia de las religiones. El concepto que nos permitirá desplegar esta mirada global no será otro que el de cultura del paisaje, que, aplicado al contexto de la civilización china, muestra ciertas peculiaridades que se deben explicar. Tradicionalmente existe una distinción entre la poesía

${ }^{1}$ Hui Shu-Lee, Exquisite Moments, West Lake E Southern Song Art, Nueva York, China Institute Gallery, 2001. Geremie R. Barme, "West Lake", Chinese Heritage Quarterly, núm. 28, diciembre de 2011. 
de tianyuan 田园 (campos cultivados y jardines) y la de shanshui 山水 (poesía de montañas y ríos). Una comienza con la poesía de Tao Yuanming 陶渊明 (365-427) y la otra con la de Xie Lingyun 谢灵运 (385-433). Esta dicotomía ha afectado tanto el estudio de la cultura del paisaje en China que, en muchas investigaciones, el jardín chino se analiza separado de la pintura de paisaje, la poesía de paisaje o los asentamientos en las montañas famosas. Sólo algunos investigadores han ido más allá de estos términos intentando establecer una red de relaciones, como en el caso de Yolaine Escande. ${ }^{2}$

Lejos de esta separación, una mirada atenta a las fuentes nos muestra una realidad totalmente diferente. La distinción tan clara entre tianyuan y shanbsui está muy alejada de lo que las fuentes dejan entrever, ya que los jardines y las villas de cultivo estaban construidos dentro de las montañas famosas, las montañas famosas eran imitadas en los jardines urbanos y evocadas en pinturas, los jardines inspiraban composiciones literarias y pictóricas, y la crítica de las rocas de jardines utilizaba los mismos conceptos en una composición de rocas situada en un jardín que en un conjunto de rocas situado en un espacio natural o en una caverna.

Debido a que necesitamos un concepto con capacidad de englobar estas diferentes manifestaciones, es más operativo para esta investigación utilizar el término paisaje en lugar de los términos en lengua china jing 景, shanshui o tianyuan. Esta estrategia nos llevará, primeramente, a superar la dicotomía shanshui-tianyuan. El término paisaje, tal y como ha sido definido por investigadores como Berque y Maderuelo, ${ }^{3}$ es una poderosa arma hermenéutica con la cual podemos unificar todas las manifestaciones que tienen que ver con el paisaje en la cultura china. El término incluye la construcción de jardines, la literatura y la pintura de paisaje, ya que se define como un constructor cultural que configura la manera en la que el hombre se relaciona con la naturaleza.

\footnotetext{
${ }^{2}$ Yolaine Escande, Montagnes et eaux : La culture du shanshui, París, Hermann Éditeurs des Sciences et des Arts, 2005.

${ }^{3}$ Augustine Berque, La Pensée paysagére, París, Archibooks-Sautereau Éditeur, 2009. (Traducción al español: El pensamiento paisajero, Madrid, Biblioteca Nueva, 2009.) Javier Maderuelo, El paisaje: génesis de un concepto, Madrid, Abada, 2005.
} 
Esta metodología es muy adecuada en el tema que nos ocupa. El lago del Oeste se formó, desde sus más tempranos comienzos, como un espacio complejo de colaboración entre trabajo humano y naturaleza. Posteriormente se volvió uno de los paisajes famosos del lejano sur, plagado de monasterios budistas y, finalmente, durante la dinastía Song del sur, el lago se convirtió en un gran jardín paisajista, rodeado de jardines imperiales, jardines privados, monasterios y villas de cultivo en la periferia. Interconectado con este proceso de constitución, el lago del Oeste también fue objeto de inspiración de todo tipo de composiciones literarias y de pinturas que abarcan múltiples aspectos tan dispares como la crítica a la situación política o la especulación estética o religiosa. Estas fuentes presentan una multitud de temas entrelazados y forman un ingente corpus que, si bien no es inabarcable, sí tiene un tamaño considerable. Ante esta enorme cantidad de fuentes y debido a que la historia del lago del Oeste cubre un periodo bastante largo, este artículo pretende ser un punto de partida que desemboque en una futura monografía específica sobre el lugar. Por eso se centra en el periodo de formación y describe el proceso y los movimientos que llevan a que un lugar alejado como Hangzhou, en el distante y pantanoso sur, acabe convirtiéndose en uno de los paisajes más famosos de China. Revisaremos así el periodo que arranca con los primeros asentamientos en la época de los Reinos Combatientes hasta la de las Cinco Dinastías, cuando Hangzhou tomó el sobrenombre de Foguo 佛国 (Reino del Buda) debido a la gran cantidad de monasterios budistas que se construyeron. Es ésta la etapa de establecimiento de un paisaje, en el que el lago del Oeste se fue configurando geográficamente a partir de los lacustres y pantanosos terrenos de la zona, para emerger como uno de los lugares más transcendentes de la memoria del paisaje en China.

\section{Formación de un paisaje}

Cuando hablamos de paisaje debemos tener en cuenta que no todo paraje natural es un paisaje. Para que lo sea, habrá de cumplir ciertos requisitos que pertenecen a la esfera de la cultura; un paisaje es siempre fruto de la interacción entre el ser 
humano y la naturaleza, en el que se mezclan propósitos de índole utilitaria y estética, y en el que, sobre todo, se produce una domesticación de la naturaleza en todos los niveles. En el caso de la cultura del paisaje en China, se identifican tres movimientos principales que funcionan de manera general:

1. El primero se relaciona con la conversión del espacio salvaje y natural en espacio civilizado e incluye dos niveles interrelacionados: uno atiende al proceso de reconversión en el que el espacio natural se transforma en tierras para el hábitat humano con sus terrenos de cultivo, canalizaciones de agua y, cómo no, espacios dedicados a la contemplación. El otro está en la esfera de lo sobrenatural y requiere la domesticación de los espíritus del lugar, sean éstos benéficos o maléficos, es decir, la conversión de una tierra poblada de espíritus ajenos, en otra en la que las dos religiones, daoísta y budista, toman el control del lugar mediante la metáfora de los paraísos de los inmortales (o reinos budistas), bien asimilando estos espíritus a su panteón, bien provocando una guerra abierta contra éstos.

2. El segundo entra en la esfera de los letrados y nos habla de cómo, partiendo de este movimiento civilizatorio realizado por las religiones budistas y daoístas, introducen el paisaje natural en la enciclopedia de lugares famosos, cantando las excelencias del paisaje en poemas y ensayos, en pinturas, visitando los lugares en excursiones, habilitando villas de cultivo y discutiendo acerca de los baremos para juzgar su excelencia. La mera presencia de una personalidad famosa en un lugar lo convertía en paisaje digno de ser rememorado.

3. El tercero se establece una vez que el paisaje ha alcanzado fama, y a partir de aquí puede ser tema de pinturas y composiciones literarias, y sus diferentes escenas paisajísticas serán imitadas en jardines imperiales y privados y en parajes naturales que tengan una apariencia semejante. Es decir, determinado paisaje se convierte en modelo de excelencia digno de imitar por la tradición.

Esta división en tres movimientos tiene propósitos aclaratorios, pues en la sucesión de la historia los tres niveles apare- 
cen superpuestos en algunos casos y no siempre en el orden descrito. Una villa de cultivo podía ejercer como elemento de conversión de espacio salvaje en espacio civilizado y, a su vez, ser incluida en la enciclopedia de paisajes por la fama del letrado que lo funda y los poemas y pinturas que le dedica; o bien, la villa, al ser abandonada, cae en el olvido y pasa de nuevo al espacio salvaje. Se establece así una red concéntrica de relaciones, desde la transformación del espacio salvaje en civilizado, de la belleza física de montañas y jardines a su evocación en poemas y pinturas, desde el jardín actual hasta toda la memoria de jardines famosos del pasado.

Si el modelo que propongo es una pauta de actuación que debe flexibilizarse cuando se aplique a lugares concretos, en el caso del lago del Oeste funciona más o menos en el orden descrito, aunque en muchas ocasiones los niveles se superponen. En la primera sección del artículo se habla de la fase temporal en la que Hangzhou y el lago del Oeste se ganaron su fama, desde los primeros asentamientos en forma de pequeño puerto en la etapa de los Reinos Combatientes hasta la dinastía Tang. En este periodo, el proceso de conversión del espacio salvaje en espacio civilizado fue formando la imagen del lago como reserva de agua para el cultivo. A su vez, en el análisis de la fundación de algunos monasterios es posible ver la importancia del control y la gestión del agua, muy relacionada con el espacio sobrenatural y los espíritus dragones del agua. Esta descripción expone el primer movimiento.

La segunda sección se dedica a la época que va desde la dinastía Tang (618-907) hasta las Cinco Dinastías. La llegada de Bai Juyi 白居易 (772-846) fue fundamental en la conformación de la fama del lago del Oeste, ya que fue él quien lo bautizo con su actual nombre y el que, con sus poemas, lo incluyó entre las metáforas de las tierras de los inmortales, lo que le permitió pertenecer a la lista de los paisajes famosos de China. El periodo de las Cinco Dinastías, aunque corto, es esencial, ya que la intensa construcción y patronazgo budista de los soberanos de la dinastía de los Qian convirtió a Hangzhou y el lago del Oeste en la imagen del Foguo.

Quedaría por describir el tercer movimiento, la conformación del modelo de paisaje codificado en la tradición, lo 
que se ha empezado a hacer en otras publicaciones dedicadas al lago del Oeste en la dinastía Song y que, sin duda, habrá que ampliar hasta cubrir posteriores dinastías, algo que excede el tamaño de este artículo. ${ }^{4}$

\section{De espacio salvaje a espacio civilizado}

En el periodo de Primaveras y Otoños, el territorio que hoy conocemos como la ciudad de Hangzhou era una tierra de nadie entre los reinos de Yue 越 (actual Zhejiang) y Wu 吴 (zona de Jiangsu), un interminable paraje de ciénagas lacustres conocido como Changhu 长湖, rodeado al oeste por las montañas de Tianmu 天目 y al este por una bahía.

Esta extensa área lacustre se formaba gracias a las mareas que atravesaban el río Qiantang 钱塘 y se depositaban en la tierra. En un lugar que actualmente estaría un poco al norte del puerto de la ciudad, se situaba un puerto llamado Xiling 西陵, desde donde el rey de Yue, Guojian 勾踐 (496-465 a.e.c.), inició su campaña contra el reino de $\mathrm{Wu} .^{5}$

En este periodo de continuas guerras, el estado de Yue fue absorbido por el poderoso estado de $\mathrm{Chu}$, hasta que, finalmente, Qin Shihuang 秦始皇 (260-210 a.e.c.) se hizo con el control de todo el territorio de estos estados. En el viaje que Qin Shihuang hizo posteriormente por el antiguo reino de Yue, construyó un puerto llamado Jintou 槿头. ${ }^{6}$ Desde allí se conectaba con la antigua capital del reino de Yue, Guiji 会稽 (cerca de la actual Shaoxing). Cuenta Sima Qian 司马 迁 (135-90 a.e.c.) que, en la zona de Qiantang (Hangzhou), las aguas eran turbulentas y peligrosas, hecho que corrobora que las crecidas de las olas del río Qiantang en aquel entonces eran de una envergadura considerable y convertían el lugar en uno por el que no era seguro transitar, teniendo en cuenta, además, que en esos momentos Hangzhou era ante to-

${ }^{4}$ Véase Antonio José Mezcua López, Experiencia del paisaje en China. "Shanshui" o la cultura del paisaje en la dinastía Song, Madrid, Abada, 2014.

${ }^{5}$ Que Weimin 阙维民, Hangzhou chengqi ji Xibu lishi tushuo 杭州城池暨西湖 历史图说, Hangzhou, Zhejiang Renmin Chubanshe, 2000, p. 11.

${ }^{6}$ Ibid., p. 6. 
do una bahía. ${ }^{7}$ Desde la montaña Taishan 台山, Qin Shihuang admiró el paisaje lacustre que se extendía por la zona de Qiantang. ${ }^{8}$ Éste fue el comienzo de la localidad de Qiantang, un pequeño enclave urbano situado en las faldas de la montaña de Baoshi 宝石.

Durante los periodos de la dinastía Han (202 a.e.c.-220 e.c.) y en el periodo de las Seis Dinastías (222-589), Qiantang lentamente se convirtió en un punto de comunicación importante de la región. El enclave urbano en ese momento disponía de un gran canal de agua que unía el puerto de Liupu 柳浦 con la colina de Fenghuang 凤凰, donde se situaban las residencias del gobernador y los órganos de gobierno. De acuerdo con la obra Shuijing 水经 de Li Daoyuan 丽道元 (427-469), había dos grandes zonas lacustres que desembocaban en el mar: Sheng minghu 圣明湖 y, al este, Pinghu 平湖, 9 y a partir de éstas se conformó luego el lago del Oeste. En la época de las Seis Dinastías, la configuración del paisaje de la bahía de Hangzhou no difería mucho de épocas anteriores, aunque el mar empezó a retirarse poco a poco. Aun así, las olas marinas que llegaban a través del río Qiantang dejaban la zona inservible desde el punto de vista agrícola, ya que estaban cargadas de agua que salinizaba los terrenos e impedía el cultivo. Entre la época de las Seis Dinastías y la dinastía Tang se establecieron numerosos asentamientos budistas, entre ellos los más famosos: el templo de Lingyin 灵隐 y el de Tianzhu 天竺, probablemente fundados más adelante, a principios de la dinastía Sui (581-618). La colonización budista comenzó y tuvo que afrontar el mismo problema que todo el mundo preindustrial: la lucha por el control y el abastecimiento de agua.

El norte de Zhejiang se caracteriza por multitud de pantanos y zonas lacustres formados por un clima continental húmedo, influido además por los múltiples tifones que afectan esa área costera del mar de China. El hábitat humano en este tipo de condiciones geográficas necesita deshacerse del agua pantanosa y salina y encontrar manantiales y pozos de agua po-

${ }^{7}$ Wang Guoping 王国平 y Pan Zhiliang 潘志良 (eds.), Xibu shangshi 西湖赏石, Hangzhou, Hangzhou Chubanshe, 2014, p. 122.

${ }^{8}$ Ibid., p. 120.

${ }^{9}$ Idem. 
table. Es precisamente en este aspecto donde entra en juego el primer movimiento: la conversión del espacio salvaje en espacio civilizado. La preparación del terreno para que fuera habitable por el ser humano iba ligada, entre otras cosas, al hallazgo de fuentes suficientes de agua potable. Esto se relacionaba, a su vez, con la presencia de seres sobrenaturales, sobre todo de dragones, con los que había que mantener relaciones adecuadas si se quería evitar desastres como inundaciones y sequías. Las leyendas que relacionan el acceso al agua potable y el control de las mareas del río Qiantang nos permiten examinar el proceso mediante el cual las fuerzas sobrenaturales de un determinado paraje se ponían al servicio de las religiones civilizatorias para convertir el paraje natural salvaje en espacio civilizado. Es a partir de este primer movimiento que comienza la transformación material e ideológica que termina transmutando el paraje natural en paisaje.

Para ilustrar lo anterior, revisemos las leyendas acerca de la fundación del altar de Yuquan 玉泉 (que luego dio lugar al monasterio del Manantial de Jade en el 938) y sobre el control de la lluvia de la montaña de Lingshan 灵山 (donde posteriormente se fundó el templo de Lingyin). Las leyendas a las que nos referimos se ambientan en los años 479-482 y se entrelazan con similar narrativa en torno a la figura del monje Tang Chao 是超 (419-492). Según la biografía recogida por Huijiao 慧皎 (497-554), el monje Tang Chao residió durante un tiempo en la montaña Lingshan practicando meditación. Un día se le presentó un dragón para pedirle que apaciguara la ira de ciertos dragones que habían sido agraviados con actividades mineras de extracción de arcilla cerca de la montaña $\mathrm{Lu}$ 庐, y que, como castigo, habían secado los pozos de agua. Seguidamente, el monje se dirigió a aquel lugar y, mediante encantamientos, convirtió a esos dragones al budismo y les pidió que pusieran fin a la sequía, a lo que accedieron..$^{10}$ En una versión muy similar se nos dice que el monje Tang Chao construyó una pequeña cabaña para meditar en Yuquan. Cuando estaba impartiendo

${ }^{10}$ Shinohara Koichi, "Biographies of Eminent Monks in a Comparative Perspective: The Function of the Holy in Medieval Chinese Buddhism", Chung-Hwa Buddhist Journal, núm. 7, julio de 1994, pp. 490-491. 
su enseñanza, apareció un anciano (un dragón) que le explicó el problema de la sequía causada por los dragones de la leyenda mencionada; en esta ocasión, sin embargo, el final es diferente, ya que, ante la petición de Tang Chao, el dragón hizo brotar agua del suelo con una palmada. ${ }^{11}$

En estas leyendas, el abastecimiento de agua es un regalo de las potencias sobrenaturales que reinan sobre el lugar, bien mediante lluvia o bien por la aparición de un manantial. La relación que se establece con los dragones muestra cómo los asentamientos budistas se van estableciendo en colaboración con las potencias sobrenaturales, y cómo se produce además una sujeción de éstas a los designios de la caridad budista. Por eso interesa señalar la relación entre abastecimiento de agua, control de la lluvia y seres sobrenaturales. El hallazgo de manantiales para el consumo de agua va ligado a la intervención del poder de la Iglesia budista como intermediaria con los seres que reinan sobre el lugar, que no sólo hace que aparezcan los manantiales que permiten el acceso al agua limpia, sino que además asume el control de la gestión de la lluvia.

Tener un abastecimiento de agua apropiado venía de la mano de la relación con las presencias sobrenaturales del lugar. Aunque también podía ocurrir que fueran las presencias sobrenaturales de los centros de poder de las montañas sagradas las que ayudaran a la conversión en espacio civilizado por medio del control del agua. Un buen ejemplo lo tenemos en las leyendas de fundación del monasterio de Hupao si 虎跑寺, situado en las laderas de la montaña Daci 大慈山 y fundado en el 817, durante la dinastía Tang. Una leyenda nos habla de cómo, en un tiempo de severa sequía, el abad del monasterio, Huan Zhong 寰中 (780-862), soñó con un inmortal que le comunicaba que el manantial del Niño (Tongzi Quan 童子 泉), situado en la montaña Hengshan 衡山, sería transportado por dos tigres a su monasterio. Cuando los tigres llegaron a

${ }^{11}$ Yao Yuqiu 姚毓璆 y Zheng Qisheng 郑祺生, “Bicao miren gui, Chuchu jin kanlian; Sui Tang shiqi Hangzhou Xihu yuanlin 碧草迷人归处处尽堪恋; 随唐时期 杭州西湖园林”, en Zhou Shanfeng 周山峰 (ed.), Hangzhou Lishi congbian zhier; Sui Tang mingiun Hangzhou 杭州历史从编之二, 隋唐名郡杭州, Hangzhou, Zhejiang Renmin Chubanshe, 1997, p. 115. También en Zhang Dai 张岱, Yuquansi 玉泉寺, en Zhang Chengde 张成德 (ed.), Zhongguo youji sanwen daxi; Zhejiang juan (shang) 中国 游记散文大系: 浙江卷 (上), Taiyuan, Shuhai Chubanshe, 2003, p. 215. 
las afueras del templo, de sus pisadas nació un hoyo de donde comenzó a brotar agua. ${ }^{12}$

En la leyenda de Hupao si, es el prestigio de la Montaña sagrada del Sur, un lugar que había sido colonizado también por el budismo, el que le da la calidad necesaria y crea una relación que aumenta su poder espiritual. Los seres sobrenaturales de la montaña de Hengshan apoyan el establecimiento del monasterio al donar un manantial, a la vez que se crea una conexión de linaje entre los dos lugares.

Hasta ahora, estas dos leyendas se refieren al abastecimiento de agua necesario para el hábitat humano; sin embargo, hay otros factores concernientes al control del agua que merecen atención. Y aquí entra en juego otro de los principales puntos "turísticos" que integraban los lugares famosos de la localidad de Qiantang hasta bien entrada la dinastía Song: no es otro que las mareas provenientes del mar Amarillo que se infiltraban en el río Qiantang y provocaban olas de gran altura y sus consecuentes inundaciones incontrolables que, además, salinizaban el terreno. Estos desbordamientos, por otro lado, eran muy frecuentes en la zona baja del río Yangzi, donde su control y la canalización del exceso de agua eran problemas que caminaban junto a la necesidad de drenar terrenos lacustres salinizados para la agricultura. El control de estos dos fenómenos, las mareas y las inundaciones del río Qiantang, es otro elemento que se debe examinar en este primer movimiento de formación de la memoria del paisaje del lago del Oeste.

En el poema de Bai Juyi "Vista de Hangzhou en primavera”, se nombra un lugar que estaba en íntima relación con este fenómeno de las olas del río Qiantang, el templo de Wu Yunmiao 伍员庙, situado actualmente en la montaña Wu. ${ }^{13}$ Wu Yun (?- 484 a.e.c.) fue un general de la época de Primaveras y Otoños, arquetipo, junto a Qu Yuan 屈原 (340-? a.e.c.), de la lealtad al gobernante. Wu Yun era nativo del estado de Chu, pero cuando su padre fue asesinado en una conspiración, tuvo que huir al reino de $\mathrm{Wu}$, donde se puso bajo las órdenes y la

${ }^{12}$ Véase Yao Yuqiu y Zheng Qisheng, "Bicao miren gui, Chuchu jin kanlian...”, op. cit., p. 115.

${ }^{13}$ Ibid., p. 117. Para el poema completo, véase Zhou Ruchang 周汝昌, Bai Juyi shixuan 白居易诗选, Beijing, Renmin Wenxue Chubanshe, 1999, p. 286. 
estima del rey He Lü 瞌闾 (514-496 a.e.c.). Después de ganar una importante batalla contra el estado de Chu, y tras la muerte de He Lü, Wu Yun cayó en desgracia cuando aconsejó al nuevo rey $\mathrm{Fu}$ Chai 夫差 (495-473) acerca del peligro de invasión del reino de Yue. Acusado de conspiración, fue obligado a suicidarse y, según algunas fuentes, su cuerpo fue arrojado al río. Posteriormente, tal y como Wu Yun predijo, Yue conquistó el reino de Wu. ${ }^{14}$ La cultura popular, como ocurrió con muchas figuras históricas, lo convirtió en un espíritu: pasó a ser el Señor de las Olas Taoshen 涛神. En Hangzhou, debido a la ferocidad que a veces tenían las mareas de río Qiantang, se relacionó este fenómeno con la figura de Wu Yun; se decía que las causaba su espíritu enfurecido que vagaba por el ultramundo sin descanso. De ahí que el templo dedicado a Wu Yun fuera una manera de aplacar su cólera. Luego veremos que la violencia de estas mareas requirió otro elemento muy importante dentro de la conformación del paisaje del lago del Oeste: la pagoda de las Seis Armonías.

La acción mágica contra los fenómenos naturales no fue suficiente. Las olas siguieron causando estragos en la zona de la bahía de Hangzhou durante todo el periodo dinástico, por lo que fue necesario un tremendo esfuerzo de movilización de recursos humanos para realizar titánicas obras hidráulicas que contribuyeron a que el mar se retirara definitivamente de la zona, lo que a su vez trajo otros problemas medioambientales. ${ }^{15}$ En esa misma época fue también cuando los paisajes de la zona de Jiangnan 江南 (que abarca las actuales provincias de Jiangsu y Zhejiang) se conformaron como lugares principales, a partir de los cuales surgió el concepto de paisaje. ${ }^{16}$ Mientras el norte estaba siendo arrasado por diferentes tribus nómadas de las estepas, en el sur, en la nueva capital, Nanjing, se refugiaron las antiguas aristocracias Han. Este repliegue hacia el sur supuso el descubrimiento, por parte de la cultura Han, de los desbordantes y voluptuosos parajes naturales de esta zona, a partir de los cuales se conformó esta nueva mirada hacia la naturaleza.

${ }^{14}$ Véase Jacçues Gernet, El mundo chino, Barcelona, Crítica, 2007, p. 67.

${ }^{15}$ Mark Elvin, The Retreat of the Elephants, an Environmental History of China, New Heaven, Yale University Press, 2004, pp. 115-165.

${ }^{16}$ Escande, Montagnes et eaux, op. cit., pp. 73-74. 
El retiro a las montañas como ideal de vida armónica en comunión con el dao fue de la mano de la transformación de la naturaleza salvaje en espacio habitable por el ser humano. El poeta Xie Lingyun fue una de las figuras clave en este proceso, pues se retiró a una villa en la bahía de Hangzhou, en un lugar que hoy corresponde a la localidad de Shangyu 上虞, entre las ciudades de Hangzhou y Shaoxing. Al ser éste un paisaje muy similar al que había en ese momento en la localidad de Hangzhou, es pertinente el examen de un fragmento del poema en prosa que el poeta escribió sobre su villa, ya que encontramos ahí una descripción de las olas del río Qiantang que se ajusta muy bien a lo que podríamos llamar una "versión china" del concepto de lo sublime. ${ }^{17}$

Las olas se levantan en su máximo, y sus ondas espumean tumultuosas.

El terror en oleadas alcanza la cúspide de su arrogancia.

Se disparan en luces a borbotones, rompen en estruendosos choques.

La espuma fluye en la superficie del mar llevada por el viento y salta hacia arriba, volando y salpicando.

Venciendo un abrupto dique, el mar se abalanza sobre las escarpaduras. Cuando se encuentra con la corriente del río, lo lleva hacia su dominio. Empieza rodeándolo rápidamente, como si cabalgara a los cielos.

Y así termina curvándose hacia abajo, de manera que se atisba el lecho del golfo;

embriagado por esta visión, el heredero al trono de Chu se curó. ${ }^{18}$

En el texto se muestran perfectamente el poder y la grandiosidad terrorífica de la naturaleza, las olas como rayos y truenos invaden el espacio; el viento, la espuma... todo un espectáculo que, mientras era la pesadilla para los campesinos que luchaban contra el daño que provocaban en las tierras ganadas a la bahía, visto a través del prisma de la mirada del poeta adquiere un carácter terapéutico. Este carácter sanador fue un tópico adscrito a la experimentación del paisaje y tiene en la poesía de Xie Lingyun uno de sus orígenes. Pero lo más importante es destacar cómo la grandiosidad de la naturaleza, además de su poder destructor -contra el que el propio Xie

17 Shanjufu 山居赋, “Poema en prosa de mi residencia en las montañas".

18 “[...] 汤汤惊波, 滔滔骇浪。电激雷崩, 飞流洒漾。凌绝壁而起岑, 横中流而 连薄。始迅转而腾天, 终倒底而见壑。此楚氠心醉于吴客, [...]”. Elvin, The Retreat of the Elephants, op. cit., p. 348. 
Lingyun tenía que luchar si quería mantener las tierras de cultivo de su villa-, también tiene un profundo poder fascinador, un efecto catártico que nace de la contemplación de las fuerzas naturales que, no olvidemos, son la manifestación del dao y su espontaneidad. Los cristales daoístas y budistas a través de los cuales Xie Lingyun observa la naturaleza impiden que la destrucción, la tragedia y esa lucha del ser humano contra lo natural se expresen como se hizo después en Occidente. Aun cuando es consciente de la desdicha que a menudo conllevan los fenómenos naturales en su transformación, la tragedia queda en segundo plano. Con todo, hay que remarcar que esta contemplación estética, donde la tragedia del sublime queda anulada por el proceso inmunizador de la filosofía daoísta, no estaba reñida con la necesidad de transformar la naturaleza salvaje y así aminorar los efectos destructivos de sus procesos. De hecho, la descripción que acabamos de citar inaugura una tradición en la contemplación del paisaje de Hangzhou que tuvo en las olas del río Qiantang su principal objeto de atención y que se expresó en posteriores dinastías en multitud de poemas y pinturas dedicados al fenómeno. Esta experiencia del paisaje ofrece un radical contraste con la encarnizada lucha que los habitantes de la zona tuvieron que entablar para controlar estas olas y, mediante enormes obras hidráulicas, ganar terreno cultivable a la bahía. Irónicamente, esta transformación de la naturaleza a largo plazo causó desequilibrios naturales que no hicieron sino aumentar las catástrofes. Pinturas, poemas y obras arquitectónicas funcionaron como una terapéutica social subconsciente que intentaba aminorar, en el plano sanador de la estética y la religión, el infortunio que la naturaleza dejaba en su feroz transformación y los inconscientes desequilibrios ocasionados por el ser humano en su lucha por el control de lo natural.

\section{Los personajes famosos visitan Hangzhou}

En la primera de las historias locales que se escribió sobre Hangzhou, cuando fue capital del imperio en la dinastía Song del sur, son numerosos los personajes de las tres sabidurías que 
se relacionan con el lugar. No podemos hacer aquí un catálogo de todos ellos, por lo que sólo mencionaremos a algunos: el alquimista Ge Hong 葛洪 (283-343), el daoísta Guo Wen 郭文 (fechas desconocidas) y otras personalidades del budismo, como la figura legendaria del monje indio $\mathrm{Hui} \mathrm{Li}$ 慧里, fundador del monasterio de Lingyin, y el mismo Tang Chao antes mencionado. Junto con estas figuras, Li Bai 李白 (701-762), Meng Haoran 孟浩然 (691-740) y muchos otros poetas letrados viajaron, ya en la dinastía Tang, a Hangzhou y compusieron poemas sobre los lugares famosos de la localidad. ${ }^{19}$ Es importante señalar que en esos momentos los puntos que más se mencionan son los monasterios de Lingyin y Tianzhu, las olas del río Qiantang $\mathrm{y}$, asociado con este fenómeno, el templo de Wu Yun. El lago, que aún estaba en proceso de formación, quedaba fuera de la lista de lugares famosos durante los siglos VII y VIII, que, si bien fueron absorbidos más adelante por el macroespacio paisajístico que conformaría el lago del Oeste, en esa época tenían un funcionamiento totalmente independiente de un lago que ni siquiera existía como tal. La relevancia de esto reside en que, en numerosos estudios, estos lugares se conciben como si siempre hubieran estado en relación con el lago del Oeste, cuando en realidad operaban de manera autónoma, ya que la idea de macroespacio unificado en torno a la figura central del lago del Oeste aún no se había forjado. En la dinastía Tang, hasta la llegada de Bai Juyi a principios del siglo Ix, el lago no tenía ninguna importancia, y fueron los templos de Tianzhu o de Lingyin, entre otros, las figuras dominantes en la apreciación de los lugares paisajísticos famosos de Hangzhou. El que el lago aún no fuera objeto de contemplación estética es comprensible si tenemos en cuenta que fue precisamente en esta época cuando nació, con un mero propósito utilitario, una reserva de agua dulce que abasteciera la ciudad y que, junto con los muros que posiblemente se comenzaban a construir en las costas de la bahía, protegiera a la población de morir de sed y

${ }^{19}$ Wang Rongchu 王荣初, "Wei nengpao de Hangzhou qu, yi ban gouliu shi ci hu 未能抛得杭州去, 一半勾留是此湖: 唐代西湖诗词”, en Zhou Shanfeng 周山峰 (ed.), Hangzhou Lishi congbian zhier; Sui Tang mingjun Hangzhou 杭州历史 丛编之二, 隋唐名郡杭州, Hangzhou, Zhejiang Renmin Chubanshe, 1997, pp. 123124. 
de hambre cuando las olas del río Qiantang salinizaban pozos y cultivos. Así pues, hasta antes del siglo Ix, la apreciación del paisaje de Hangzhou se focalizaba en las descripciones de la ola conectadas con el concepto de lo sublime. Los poemas dedicados a los templos de Tianzhu y Lingyin, por su parte, estaban más en consonancia con la estética clásica del paisaje, siempre imbuida por ese carácter aéreo y sereno que les da su fuerte filiación con conceptos budistas. Respecto a las descripciones de la ola, y como ejemplo más representativo, destaca el poema de Meng Haoran "Subiendo al pabellón del Alcanfor con Yan para ver las olas del río Qiantang”.

En la distancia de cien lis se escucha el vibrar de los truenos, como sonidos de cuerdas interrumpidas en su tañer.

Juntos partimos a caballo desde la prefectura, al lado del río esperamos para contemplar la ola.

El sol brilla entre las distantes nubes del otoño,

flotando en el cielo inmenso; el mar de Bohai.

La ola comienza a llegar como el trueno y, asustado, tiemblo. ${ }^{20}$

En primer lugar, este poema cuenta que se había habilitado un pequeño pabellón cerca del río, a unos cinco lis ${ }^{21}$ hacia el sur, ${ }^{22}$ para la contemplación del espectáculo de la ola. El poema comienza con sonidos a lo lejos que, como cuerdas de cítara qin, retumban en la distancia, truenos que focalizan la imagen de las olas en su aspecto de fenómeno natural que se manifiesta en toda su terrible dimensión. Luego vienen imágenes de relativa calma que ofrecen un contrapunto al abrupto final, cuando la ola comienza a formarse y el miedo se desplaza y provoca sensaciones físicas en el poeta, una dimensión corporal que se introduce con la inclusión de los últimos ideogramas sheng han (crece el temblor). En este poema estamos ante un sublime

\footnotetext{
20 与颜钱塘登樟亭望潮作

百里闻雷震, 鸣弦暂辍弹。

府中连骑出, 江上待潮观。

照日秋云迥, 浮天渤澥宽。

惊涛来似雪, 一坐凛生寒.

La versión original del poema está en la obra citada en la nota anterior (ibid.,

${ }^{21}$ Un li equivale a $1.6 \mathrm{~km}$.

${ }^{22}$ Wang Rongchu, "Wei nengpao de Hangzhou qu...”, op. cit.
} p. 124). 
inminente, que parte de las imágenes lejanas para instalarse en su más tremenda manifestación en los dos últimos versos. En este caso no existe ninguna terapéutica, sólo una sensación de inminencia en la que lo terrible queda como imaginado, intuido por esa sensación y ese temblor que surgen ante las aguas que se elevan.

Estas imágenes paisajísticas sublimes, nacidas de la contemplación de las olas del río Qiantang, contrastan con los poemas dedicados a las excursiones y estancias en los templos de Lingyin y Tianzhu. Toda esta terribilità de la naturaleza se transforma en tranquilas visiones que se funden en las nieblas de la extinción de la conciencia budista. Como ejemplo de esta otra visión adscrita a los paisajes de la ciudad de Hangzhou tenemos un poema de Quan Deyu 全德舆 (759-818):

Converso con los monjes en los monasterios de Tiazhu y de Lingyin mientras allí me hospedo.

Un camino de piedra y un arroyo fluido separa los dos monasterios, a menudo busco la campana y escucho su sonido fundirse con las montañas,

la mitad de los monjes vive en el medio de la colina, ${ }^{23}$ nubes blancas ocupan el azul lapislázuli de la sierra. ${ }^{24}$

Tras la composición espacial del primer verso, de nuevo son los sonidos en la lejanía los que guían el tempo del poema y nos introducen en una doble fusión a partir de la cual giran todas las imágenes. En primer término se establece la absorción del remanente sonido de la campana en las montañas; en segundo, son las propias montañas las que acaban siendo engullidas por el avance implacable de las nubes. El resto del poema sirve como mera introducción espacial, los lugares y los monjes que allí residen quedan como marco distante de la disolución de las formas en el vacío. Y es que aquí estamos ante la experiencia del paisaje que alcanzó las más altas cotas de realización humana.

\footnotetext{
${ }^{23}$ El ideograma zhong en el verso se refiere a la parte media de la montaña.

24 戏赠天竺灵隐二寺寺主

石路泉流两寺分, 寻常钟馨隔山闻。

山僧半在中峰住, 共占青峦与白云。

Wang Rongchu, "Wei nengpao de Hangzhou qu...”, op. cit., p. 122.
} 
Son éstas las dos visiones del paisaje que se establecen en esta época. La primera, más cercana a lo sublime, nos pone en relación con esas fuerzas incontrolables de la naturaleza, y la segunda, en su polo opuesto, busca en el paisaje el lugar propicio para el cultivo interior, el paisaje que, debido a sus especiales características, es el hogar de monjes y hombres del dao. La llegada de Bai Juyi marca un punto de inflexión entre estos dos extremos, ya que, al introducir el lago en el centro de la experiencia paisajística, abre las vías para que, desde esta contemplación de la naturaleza en su versión de tierras de los inmortales, la apreciación estética se abra a un nuevo camino que inaugura la larga tradición paisajística del lago del Oeste.

Bai Juyi llegó en el 822, y su figura fue clave en la conformación del paisaje del lago del Oeste, tanto en un plano material de intervención paisajística como en el conceptual. En esos momentos, además de los lugares mencionados, estaba el monasterio de Gushan 孤山 (fundado en la dinastía Sui) en la colina Solitaria, que se adentra en el lago. Bai Juyi compuso el poema “Huting wanggui” 湖亭晚归 (“Volviendo a casa desde el kiosco del lago"), que muchos investigadores relacionan con el famoso kiosco que posteriormente fue llamado Wang Huting 望湖亭, lugar desde el que se aprecia una notable panorámica del lago y la colina Solitaria. ${ }^{25}$ En la zona administrativa, localizada en la actual colina de Fenghuang 凤凰, se situaban también numerosos jardines a los que Bai Juyi dedicó algunas composiciones poéticas. ${ }^{26}$ Es de destacar que en ninguna se establece relación con el lago, salvo la dedicada al kiosco. Esto demuestra que en ese momento el lago no tenía la más mínima importancia en lo que a lugares famosos se refiere, y que fue Bai Juyi el que comenzó a prestarle atención.

La fama del lago comenzó, pues, con la llegada de Bai Juyi; fue él quien hizo una de las primeras intervenciones conocidas para drenar los sedimentos del lago y construir un acceso que llevara desde sus orillas hasta la colina Solitaria, que fue conocida como Baidi 白堤 (literalmente, el dique del señor Bai). También, fue él quien empezó a asimilar el lago del Oeste y su

${ }^{25}$ Véase Yao Yuqiu y Zheng Qisheng, "Bicao miren gui, Chuchu jin kanlian...”, op. cit., p. 114.

${ }^{26}$ Ibid., p. 116. 
paisaje al de las tierras de los inmortales. Como se comentó en la introducción, la asimilación de los paisajes famosos a las tierras de los inmortales era uno de los movimientos mediante los cuales una determinada área se transformaba en paisaje. Los poemas de Bai Juyi tienen un doble valor: por un lado, comienzan la asimilación del paraje del lago a las tierras de los inmortales; por otro, instauran la tradición literaria que pone el lago en la enciclopedia de los lugares paisajísticos dignos de ser visitados. A partir de Bai Juyi, el lago comenzó a ser el centro neurálgico en torno al cual giró el paisaje de Hangzhou, no sólo por los poemas que le dedicó, sino también porque su mera presencia bastó para bautizar el lugar con el aura mágica que posteriormente se le atribuyó a uno de los más importantes poetas de la dinastía Tang. A Bai Juyi también se le debe el nombre de lago del Oeste. Hasta ese momento, el lago era conocido, entre otros nombres, como Changhu, Qiantanghu o Shanghu 上湖, $\mathrm{y}$ fue Bai Juyi el primero en llamarlo lago del Oeste, Xihu 西湖.

De las composiciones literarias que Bai Juyi escribió al respecto, destaco tres: la primera es un ensayo en prosa titulado “Qiantang hushi ji” 錢塘湖石記, en el que claramente se aprecia la función esencialmente utilitaria del lago y su vital importancia para la agricultura de la zona. Cuando el poeta llegó a Hangzhou, eran los años en los que el poder central, desgastado en luchas internas y rebeliones, aún conservaba autoridad sobre los territorios del sur. ${ }^{27}$ No obstante, la situación que encontró Bai Juyi distaba mucho de ser ideal: la negligencia de los anteriores gobernadores había dejado los diques sin reparar, y la excesiva sedimentación causaba la subida del nivel de sus aguas, lo que daba pie a inundaciones que dejaban las tierras inservibles para el trabajo agrícola. A su vez, los cambios en el ritmo de las lluvias producían sequías inesperadas, nefastas para un cultivo tan delicado como el arroz, o inundaciones repentinas que llegaban hasta los mismos muros de la ciudad (construidos durante la dinastía Sui para detenerlas) y, de nuevo, arruinaban los

${ }^{27}$ A partir de la segunda mitad del siglo ix, los territorios del sur comenzaron a tener más autonomía hasta la caída oficial de Tang en el siglo x; la administración de Tang fue declinando después de varias rebeliones que, aunque nacieron en el norte, afectaron también al sur. Véase Denis Twitchett (ed.), The Cambridge History of China. Volume 3: Sui and T'ang China, 589-906 AD, Part I, Cambridge, Cambridge University Press, 1979. 
campos y los convertían en ciénagas. En esos periodos el lago era, sobre todo, una gran reserva de agua que funcionaba como eje vital para la agricultura, y una de las principales fuentes de abastecimiento de agua potable para la ciudad. Casi cuarenta años antes, entre los años 766 y 779, el gobernador Li Mi 李 泌 (722-789) había hecho construir seis pozos en la ciudad con agua que venía desde el lago y que Bai Juyi también se dedicó a drenar para volverlos operativos de nuevo. Además, emprendió diversas intervenciones para reparar los diques de contención del agua y limpiar los sedimentos del lago y convertirlo en una saneada reserva de agua que era de vital importancia para la zona. La construcción del dique Bai entra en este programa de saneamiento, en el que también vislumbramos propósitos de intervención paisajística; con la construcción del puente, se abrieron nuevas vistas al paisaje, a la vez que se facilitó el acceso hacia Gushan, que, como hemos visto, en ese entonces era uno de los crecientes puntos turísticos en las vistas del lago. ${ }^{28}$

La segunda composición nos adentra en el plano de las ideas y muestra cómo el lago pasa de ser una reserva de agua a un espacio transmutado por la contemplación estética, un lugar paradisiaco donde moran los inmortales. El poema se titula "Volviendo al atardecer del lago del Oeste me vuelvo para contemplar el monasterio de Gushan", ${ }^{29}$ y se constituye en el primer texto conservado en el que el lugar recibe el nombre de lago del Oeste:

Lago de sauces, isla de pinos, templo de lotos, al atardecer regreso en mi barca desde el altar del dao.

Gotean los nísperos bajo la lluvia,

las hojas de palma se balancean sobre el agua, fresca brisa.

${ }^{28} \mathrm{Yu}$ Jin 余荩, “He jun xian gande, li bieqing yiyi: Hangzhou yu Bai Juyi, 合 郡咸感德, 离别情依依: 杭州与白居易”, en Zhou Shanfeng 周山峰 (ed.), Hangzhou Lishi congbian zhier; Sui Tang mingiun Hangzhou 杭州历史从编之二, 隋唐名郡杭 州, Hangzhou, Zhejiang Renmin Chubanshe, 1997, pp. 168-171. En este capítulo se encuentra el texto entero puntuado y comentado.

29 柳湖松岛莲花寺, 晚动归桡出道场。

卢橘子低山雨重, 栟㭣叶战水风凉。

烟波澹荡摇空碧, 楼殿参差倚夕阳。

到岸请君回首望, 蓬莱宫在海中央.

Bai Juyi, “Xihu wanggui hui gushansi zengzhuke” 西湖晚归回望孤山寺赠诸 客, en Zhou Ruchang 周汝昌, Bai Juyi shixuan 白居易诗选, Beijing, Renmin Wenxue Chubanshe, 1999, p. 287. 
Niebla y olas flotan en el vacío lapislázuli, pabellones y palacios yacen (desiguales) en la puesta de sol. Por favor, señor, gire la cabeza y mire hacia la orilla, el palacio de Penglai está en el centro del mar.

Este poema, lleno de matices y movimientos visuales, parte de un espacio poético transformado por las imágenes de los sauces, el lago del Oeste, la isla de los pinos, la colina Solitaria y el templo de los lotos, el monasterio Gushan. Se produce un movimiento de travelling en el que, desde la vista general del lago, nos acercamos a la colina Solitaria y, desde ahí, al templo. Si esta primera imagen nos sitúa en un espacio panorámico, la segunda nos introduce en una escala de tiempo concreto, el poeta regresa en su barca. Los siguientes versos comienzan un retruécano visual. Como auténticas instantáneas, nos llevan desde los primeros planos de las gotas cayendo del níspero y las hojas de palma hacia un movimiento rasante sobre las olas y la niebla del lago y, por último, a pabellones y palacios contra la puesta de sol. A partir de este verso, es como si el autor hubiera entrado en el tiempo del mito, el poema nos lleva del espacio poético al espacio del mito, que queda sellado en la imagen final: el lago se ha transformado en el mar del Este, y la colina Solitaria, en la isla de Penglai. Este poema marca, así, un punto de inflexión. Por un lado, el lago queda bautizado con el nombre que le dará fama; por otro, al ser asimilado su espacio a la tierra de los inmortales, entra de lleno en la categoría de zona adecuada para el cultivo interior al que las personalidades más elevadas podrán retirarse.

Junto con esta conversión total en espacio mítico, en los poemas de Bai Juyi también se produce una transformación del espacio desde el universo de la imagen poética hasta el de la imagen pictórica. Se podría decir que la tradición pictórica del lago del Oeste comienza con el primer verso de una de sus composiciones más famosas sobre el lago, "Primavera sobre el lago": ${ }^{30}$

La primavera llegó transformando el lago en una pintura, desordenadas colinas rodean las láminas del agua.

30 “湖上春来似画图, 乱峰围绕水平铺 [...]”. Bai, Juyi Chunti hushang 春題湖 上, en Zhou Ruchang, Bai Juyi shixuan, op. cit., p. 288. 
En el primer verso hay una dicotomía entre movimiento y quietud; por un lado tenemos la llegada de la primavera, lento despertar de flores brotando sobre los árboles que desemboca en el espacio estático y quieto de una pintura. El color de nuestra visión se transforma en gradaciones de grises y aguadas de tinta. Hay que tener en cuenta que el final de la dinastía Tang, aunque presenta un vacío importante en la historia de la pintura, es el periodo de remanso que dio pie a las grandes vistas macrocósmicas de las Cinco Dinastías y la dinastía Song del norte. La comparación que Bai Juyi hace en estos versos nos introduce en el tópico de ut pictura hortus ${ }^{31}$ que, durante la dinastía Song, tuvo un desarrollo considerable y se centró en la habilidad del espacio pictórico para recrear la verdadera resonancia vital de los paisajes naturales. Este recurso metafórico entre paisaje y pintura a través del medio literario fue, en la siguiente dinastía, una de las mejores maneras de juzgar la belleza de jardines y montañas. La postura de Bai Juyi se centra en que, mediante la comparación del espacio natural con el medio pictórico -es decir, mediante su artealización, para utilizar el concepto de Alain Roger- $-{ }^{32}$ el espacio natural pasa a la categoría de lugar paisajístico. No obstante, lo que introduce al lago en la esfera de la pintura no es la acción humana, sino la misma naturaleza, que con su capacidad de transformación a través de las cuatro estaciones es una pintura viviente. En este sentido, la acción humana, a diferencia de la teoría de Roger, se mantiene sumisa a los dictados del cambio de la naturaleza. La comparación entre paisaje y pintura a través del poema nos introduce en esa red de relaciones interdisciplinares; así, se construye el principio de un paisaje caleidoscópico en el que, a partir de lo natural, se establecen múltiples movimientos que nos llevan por diferentes espacios: el poético, el pictórico o el del diseño de jardines. El paisaje se va expandiendo en diferentes medios $\mathrm{y}$ distintos niveles mentales.

${ }^{31}$ Con esta variación de la locución horaciana Ut pictura poesis nos referimos al debate frecuente en la cultura del paisaje en China según el cual los jardines y los paisajes naturales son comparables con pinturas, y viceversa, lo que señala la capacidad que tiene la pintura de recrear la verdadera esencia del paisaje. Véase Mezcua López, Experiencia del paisaje en China, op. cit. Véase también Roger Alain, Breve tratado del paisaje, Madrid, Biblioteca Nueva, 2007, pp. 44-49.

${ }^{32}$ Alain, Breve tratado del paisaje, op. cit., pp. 21-25. 
Con la llegada de Bai Juyi a Hangzhou, los movimientos que tenían que ocurrir para que un paraje se convirtiera en paisaje convergieron en su persona. Bai Juyi, primeramente, puso atención a los aspectos "utilitarios" del lugar —drenaje de aguas, construcción de diques, reparación de canales de agua para regadío-, para a continuación embellecerlo con las intervenciones de diseño del paisaje. Seguidamente, su producción poética puso el lago en la lista de los paisajes famosos, lugares metáfora de los paraísos de los inmortales. Hasta tal punto llegó la influencia que Bai Juyi ejerció sobre la imagen del lago del Oeste que, ya en siglo XI, Su Shi 苏轼 (1036-1101) utilizó la figura de Bai Juyi y sus intervenciones paisajísticas para reclamar ayuda financiera a la corte de Song con el fin de devolver al lago el esplendor que había tenido en la dinastía Tang. Si se piensa en que hasta la llegada de Bai el lago era casi insignificante entre los lugares paisajísticos de Hangzhou, se notará el alcance de que un determinado paisaje haya sido habitado por una personalidad famosa en el pasado, ya que le dio un prestigio que, de cara a tiempos posteriores, lo convirtió en lugar arquetipo al que había que intentar emular en su esplendor.

\section{Las Cinco Dinastías y la imagen del Foguo}

Después de la marcha de Bai Juyi, el poder central fue perdiendo el control de las zonas del sur, que se dividieron en pequeños estados independientes. Entre las provincias de Jiangsu y Zhejiang se instaló el reino de Wuyue, fundado por Qian Liu 钱镠 en el 907. Este corto periodo de no más de setenta años (terminó en el 978) fue crucial en el desarrollo del paisaje del lago del Oeste y de la ciudad de Hangzhou.

Entre el final de la dinastía Tang y las Cinco Dinastías, se produjeron en China importantes cambios socioeconómicos. Desde las zonas del centro-norte, devastadas por las continuas guerras, se produjo una migración hacia el sur, a los valles del río Huai y la cuenca baja del río Yangzi, Fujian, Hunan o Guangdong. Aunque siguieron siendo el lejano sur, rústico e incivilizado, comenzaron un rápido desarrollo de su agricultura y de la actividad comercial. Entre estos estados independientes, 
el reino de Wuyue fue uno de los más prósperos debido a que se vio poco afectado por las continuas guerras, lo que le permitió concentrarse en la explotación de sus recursos agrícolas y establecer rutas comerciales fluviales. ${ }^{33}$

La ciudad de Hangzhou fue la capital del estado y el centro de esta prosperidad económica, lo que implicó que el territorio pasara de ser un mero lugar administrativo a ser el punto neurálgico de toda la actividad política, económica y cultural. Qian Liu realizó un programa muy ambicioso de construcción de diques, reparación de canales de regadío, control de aguas y explotación agrícola de zonas lacustres, y estableció vías de comercio fluvial. Como parte de ese plan, el lago del Oeste recibió gran atención. Se estableció como prioridad el drenaje de los sedimentos que se habían acumulado en el lago como consecuencia del descuido en las épocas de turbulencias políticas. Si de la dinastía Tang no ha quedado ninguna fuente que nos hable de jardines que aprovecharan las vistas del lago, en este periodo se comenzó la construcción de jardines y lugares que lo concebían como principal elemento de contemplación estética. En la montaña Wu 吴 se construyó el jardín Nonghua yuan 秾华源园, desde el que se podían ver el lago y el kiosco Jianghuting 江湖亭 (el kiosco para ver el río y el lago), situado en uno de los puntos más altos y que, como su nombre lo indica, estaba concebido para disfrutar del panorama del lago y del río Qiantang. ${ }^{34}$ Otro jardín, el de Xi yuan 西园, se ubicó justo en las orillas del lago, en las afueras de la puerta de Yongjin men 涌金门, ${ }^{35}$ abierto al paisaje de montañas que rodea al lago y desde el que también se podían disfrutar las vistas de las olas del río Qiantang. ${ }^{36}$

${ }^{33}$ Véase Naomi Standen, “The Five Dynasties”, en Denis Twitchett y Paul Jakov Smith (eds.), The Cambridge History of China. Volume 5: The Sung Dynasty and its Precursors, 907-1279, Cambridge, Cambridge University Press, 2009, pp. 38-132.

${ }^{34}$ Yao Yuqiu 姚毓璆 y Zheng Qisheng 郑祺生, “Liuzhu xihu shui, ting xie zhui qunshan 留住西湖水, 亭榭缀群山”, en Zhou Shanfeng 周山峰 (ed.), Hangzhou Lishi congbian zhisan; Wuyue shoufu Hangzhou 杭州历史从编之三: 吴越首府杭州, Hangzhou, Zhejiang Renmin Chubanshe, 1997, p. 143.

${ }_{35}$ Que no hay que confundir con otro jardín de la dinastía Tang con el mismo nombre, pero situado en la zona administrativa de la montaña Fenghuang, del que se sabe que no tenía ninguna vista abierta al lago. Véase Yao Yuqiu y Zheng Qisheng, "Bicao miren gui, Chuchu jin kanlian...”, op. cit., p. 116.

${ }^{36}$ Yao Yuqiu y Zheng Qisheng, "Liuzhu xihu shui, ting xie zhui qunshan”, op. cit., p. 143. 
Si en la dinastía Tang fueron los poemas de Bai Juyi los que le dieron entidad estética al lago, en el periodo Wuyue fueron los jardines pensados para disfrutar de la vista los que lo transformaron en el centro de la actividad paisajística, primer paso para convertirse en el macrojardín que fue en la dinastía Song. El lago pasó así de ser un estado mental imbuido por los poemas de Bai Juyi, a una atmosfera material en la que no sólo la poesía le dio entidad al paisaje contemplado, sino que también los jardines comenzaron una cadena de paisajes caleidoscópicos que tiene en el principio de yuan zhong yuan (el jardín dentro del jardín) su principal criterio estético de desarrollo. ${ }^{37}$

Además de la construcción de jardines, en este periodo se levantó una ingente cantidad de edificios y monumentos afiliados al budismo: pagodas, monasterios, templos, esculturas y relieves conformaron la imagen del Reino de Buda (Foguo) por el que la ciudad de Hangzhou fue conocida en adelante. Para entender esto tenemos que considerar que los sucesores de Qian Liu-Qian Zuo 錢佐 (928-947) y, sobre todo, Qian Chu 錢俶 (929-998) - , basándose en el modelo de la anterior dinastía Tang, y a pesar de las reacciones antibudistas en el norte por parte de los Zhou posteriores (951-960), escogieron el budismo como principal apoyo ideológico del nuevo estado. A su vez, el budismo fue el arma diplomática que le permitió al reino de Wuyue establecer relaciones comerciales con Japón y Corea, a donde se enviaron varias embajadas en busca de las sutras que se habían perdido en las revueltas antibudistas.

Teniendo en cuenta lo que se acaba de comentar, es fácil comprender por qué Hangzhou se convirtió en la imagen del Foguo. Hangzhou era ahora el último paraíso de prosperidad a salvo de las guerras y la barbarie continua que reinaba en el fragmentado imperio. Durante el reinado de Qian Chu, este patronazgo se reforzó hasta el punto de que Wuyue se convirtió en un refugio para el budismo, fuertemente perseguido en el

${ }^{37}$ El concepto de yuan zhong yuan 园中园 se refiere al principio según el cual, dentro de parques y territorios paisajísticos de grandes dimensiones, se incluyen jardines independientes de menor tamaño que, en muchas ocasiones, aludían a los espacios exteriores que los englobaban aprovechando sus vistas en profundidad, y que además presentaban referencias a jardines famosos del pasado o a letrados que habían poseído esos jardines como una manera de emparentarse con sus referentes éticos confucianos, daoístas o budistas de los periodos anteriores. 
norte. Por eso, esta imagen de paraíso budista necesita labrar su leyenda con base en la construcción de enclaves de esta identidad que transformen el paraje natural en la tierra donde los budas y los bodisattvas puedan vivir. Las tres pagodas que aún se conservan se erigieron al final de este periodo: Liuhe Ta 六和塔, Leifeng $\mathrm{Ta}$ 雷峰塔 $\mathrm{y}$ Baochu $\mathrm{Ta}$ 保敊塔.

La primera, Liuhe Ta, se levantó casi al final de ese periodo, hacia el 970, y nos conecta con la necesidad de controlar las olas del río Qiantang, relacionadas con el espíritu de Wu Yun, que mostraba a través de ellas su cólera. La construcción de la pagoda es un instrumento de magia ritual que marca la dominación budista sobre los seres mágicos que, con su hostilidad, perjudican las actividades humanas. Los diques para el control de las aguas no eran suficientes, tenía que haber una intervención en el plano sobrenatural para que el espacio civilizado pudiera establecerse de manera correcta, y eso se consiguió con la pagoda.

Leifeng Ta se fundó ya en los años en que el imperio Song había prácticamente unificado el territorio en torno a los Zhou posteriores. La tradición cuenta que se construyó como una ofrenda de curación en honor de la consorte Huang 黄; sin embargo, tal y cómo comenta Eugene Wang, esta atribución resulta problemática. Aunque los datos parecen indicar que, efectivamente, estuvo dedicada a una de las consortes de Qian $\mathrm{Chu}$, en las fuentes no hay ninguna consorte Huang, lo que pudo ser un error de transcripción. Lo que sí parece claro es que en sus ladrillos se introdujo el Dharani-sutra, un sutra que ya había sido grabado en piedra y erigido en forma de pilar en varios monasterios por Qian Liu y que fue muy popular en la dinastía Tang. ${ }^{38}$ Qian Chu se identificó, asimismo, con la figura del emperador indio maurya Ashoka, soberano que difundió el budismo en India y que favoreció su expansión por el sudeste asiático. La figura de Ashoka en la tradición budista estaba asimilada a la del Karavantin de la tradición india, el rey universal que gobierna en justicia y benevolencia, una imagen que

${ }^{38}$ Eugene Wang, "Tope and Topos: The Leifeng Pagoda and the Discourse of the Demonic", en Judith Zeitlin, Lydia Liu y Ellen Widme (eds.), Writing and Materiality in China: Essays in Honor of Patrick Hanan, Cambridge, Harvard University Asia Center, 2003, pp. 488-552. 
se asemeja bastante a la figura del Hijo del cielo de la tradición confuciana de China.

De cara a la historia, el éxito más clamoroso de Qian Chu fue someterse al recién fundado imperio Song, con lo que evitó la destrucción de la riqueza cultural y económica que había construido. Debido a esto, Hangzhou y el lago del Oeste siguieron siendo el país de Buda en la dinastía Song, y llegaron a tener más de trescientos monasterios budistas en sus inmediaciones. En la siguiente dinastía vino la eclosión total del paisaje de Hangzhou y del lago del Oeste, época en la que se convirtió en el macrojardín que sirvió de modelo a imitar en posteriores dinastías.

\section{Conclusiones}

Después de este largo recorrido por la formación del paisaje del lago del Oeste, y a modo de recapitulación, hay que decir que este artículo pretende ser un punto de partida en el que las bases metodológicas interdisciplinares y el modelo teórico de investigación queden bien definidos para futuras investigaciones sobre este lugar. A partir de estas premisas, el trabajo se enfocó en los primeros y múltiples factores que concurrieron para que se formara el lago del Oeste y en cómo fue ganando fama hasta convertirse en miembro del "club" de los paisajes famosos de China. En el proceso se mostró que el lugar no nació, ni mucho menos, con un propósito estético, sino que fue producto de un desarrollo civilizatorio, en el que las necesidades de adaptación y salvaguarda de un medio natural de determinadas características son los primeros movimientos que configuran el paisaje del área. Los puntos de interés paisajístico en esos primeros momentos, desde el siglo IV hasta el IX, estuvieron centrados en otros lugares, como la contemplación de la ola en el río Qiantang o la visita a los dos templos de Tianzhu y Lingyin, sitios que, absorbidos luego en la onda expansiva macrocósmica del lago, tuvieron al principio un funcionamiento autónomo. Posteriormente, la llegada de Bai Juyi marcó un punto de inflexión en el que el lago comenzó a ser concebido desde la contemplación paisajística. Las poesías que le dedica 
al lago, así como sus intervenciones materiales, lanzaron el paisaje a la fama, que se expandió en el periodo de las Cinco Dinastías. Por último, en este corto pero intenso periodo se conformó la imagen de Hangzhou como Foguo, donde los múltiples monasterios budistas y jardines que se construyeron a orillas del lago lo ubican como centro neurálgico de la experiencia paisajística que explotó en el periodo Song con la llegada de personalidades como Lin $\mathrm{Bu}$ 林逋 (967-1028) y Su Shi (1037-1101), y, finalmente, con el establecimiento de la capital en 1127.

Dirección institucional del autor:

Facultad de Filosofía y Letras

Universidad de Granada

Campus Universitario de la Cartuja s/n

18071, Granada, España

\section{Bibliografía}

Alain, Roger, Breve tratado del paisaje, Madrid, Biblioteca Nueva, 2007.

BARME, Geremie R., "West Lake”, Chinese Heritage Quarterly, núm. 28, diciembre de 2011. [ $<\mathrm{www}$.chinaheritagequarterly.org/editorial.php? issue $=028>$, consultado en diciembre de 2105.]

Berque, Augustine, El pensamiento paisajero, Madrid, Biblioteca Nueva, 2009.

Berque, Augustine, La Pensée paysagère, París, Archibooks-Sautereau Éditeur, 2009.

Elvin, Mark, The Retreat of the Elephants, an Environmental History of China, New Heaven, Yale University Press, 2004.

Escande, Yolaine, Montagnes et eaux : La culture du shanshui, París, Hermann Éditeurs des Sciences et des Arts, 2005.

Gernet, Jacques, El mundo chino, Barcelona, Crítica, 2007.

HuI, Shu-Lee, Exquisite Moments, West Lake E Southern Song Art, Nueva York, China Institute Gallery, 2001.

MAderuelo, Javier, El paisaje: génesis de un concepto, Madrid, Abada, 2005.

Mezcua López, Antonio José, Experiencia del paisaje en China. "Shanshui" o la cultura del paisaje en la dinastía Song, Madrid, Abada, 2014. 
QuE, Weimin 阙维民, Hangzhou chengqi ji Xibu lishi tushuo 杭州城 池教西湖历史图说, Hangzhou, Zhejiang Renmin Chubanshe, 2000.

SHINOHARA, Koichi, "Biographies of Eminent Monks in a Comparative Perspective: The Function of the Holy in Medieval Chinese Buddhism”, Chung-Hwa Buddhist Journal, núm. 7, julio de 1994, pp. 477-500.

Standen, Naomi, “The Five Dynasties”, en Denis Twitchett y Paul Jakov Smith (eds.), The Cambridge History of China. Volume 5: The Sung Dynasty and its Precursors, 907-1279, Cambridge, Cambridge University Press, 2009, pp. 38-132.

TwitchetT, Denis (ed.), The Cambridge History of China. Volume 3: Sui and T'ang China, 589-906 AD, Part I, Cambridge, Cambridge University Press, 1979.

WAng, Eugene, "Tope and Topos: The Leifeng Pagoda and the Discourse of the Demonic", en Judith Zeitlin, Lydia Liu y Ellen Widme (eds.), Writing and Materiality in China: Essays in Honor of Patrick Hanan, Cambridge, Harvard University Asia Center, 2003, pp. 488-552.

WANG, Guoping 王国平 y Pan Zhiliang 潘志良 (eds.), Xibu shangshi 西湖赏石, Hangzhou, Hangzhou Chubanshe, 2014.

WANG, Rongchu 王荣初, "Wei nengpao de Hangzhou qu, yi ban gouliu shi ci hu 未能抛得杭州去, 一半勾留是此湖: 唐代西湖诗词”, en Zhou Shanfeng 周山峰 (ed.), Hangzhou Lishi congbian zhier; Sui Tang mingiun Hangzhou 杭州历史从编之二, 隋唐名郡杭 州, Hangzhou, Zhejiang Renmin Chubanshe, 1997, pp. 120-145.

YAO, Yuqiu 姚毓璆 y Zheng Qisheng 郑褀生, “Bicao miren gui, Chuchu jin kanlian; Sui Tang shiqi Hangzhou Xihu yuanlin 碧草迷人归处处尽堪恋; 随唐时期杭州西湖园林”, en Zhou Shanfeng 周山峰 (ed.), Hangzhou Lishi congbian zhier; Sui Tang mingjun Hangzhou 杭州历史从编之二, 隋唐名郡杭州, Hangzhou, Zhejiang Renmin Chubanshe, 1997, pp. 109-119.

YAO, Yuqiu 姚毓璆 y Zheng Qisheng 郑祺生, “Liuzhu xihu shui, ting xie zhui qunshan 留住西湖水, 亭榭缀群山”, en Zhou Shanfeng 周山峰 (ed.), Hangzhou Lishi congbian zhisan; Wuyue shoufu Hangzhou 杭州历史从编之三: 吴越首府杭州, Hangzhou, Zhejiang Renmin Chubanshe, 1997, pp. 141-151.

Yu, Jin 余荩, “He jun xian gande, li bieqing yiyi: Hangzhou yu Bai Juyi, 合郡咸感德, 离别情依依: 杭州与白居易”, en Zhou Shanfeng 周山峰 (ed.), Hangzhou Lishi congbian zhier; Sui Tang mingiun Hangzhou 杭州历史丛编之二, 隋唐名郡杭州, Hangzhou, Zhejiang Renmin Chubanshe, 1997, pp. 165-177. 
ZHANG, Chengde 张成德 (ed.), Zhongguo youji sanwen daxi; Zhejiang juan (shang) 中国游记散文大系: 浙江卷 (上), Taiyuan, Shuhai Chubanshe, 2003.

ZHou, Ruchang 周汝昌, Bai Juyi shixuan 白居易诗选, Beijing, Renmin Wenxue Chubanshe, 1999. 